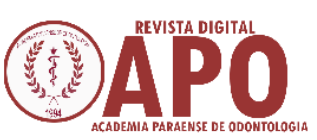

\title{
Autotransplante dentário: uma alternativa viável para a reabilitação oral
}

\author{
Autotransplantation of teeth - a viable alternative to oral rehabilitation
}

\author{
Éricka Evelyn Neves Duarte ${ }^{1}$ \\ Isadora Regiane Rodrigues Macedo ${ }^{1}$ \\ Waldner Ricardo Souza de Carvalho ${ }^{2}$ \\ Henrique do Couto Oliveira ${ }^{3}$ \\ Márcio Ruffeil Cristino ${ }^{4}$ \\ Nicolau Conte Neto ${ }^{5}$
}

\section{Resumo}

O autotransplante dentário consiste em uma técnica caracterizada pela substituição de um elemento perdido ou ausente por um elemento transplantado, geralmente um terceiro molar, para um alvéolo pré-existente ou criado cirurgicamente. É uma técnica cirúrgica relativamente simples, associada a taxas de sucesso na ordem dos $90 \%$. No entanto, pode ser influenciada pela idade do paciente, fase de desenvolvimento radicular, erupção dentária e outros fatores. Apesar das possíveis complicações dessa técnica, as vantagens econômicas e a otimização do tempo cirúrgico tornam este procedimento uma opção de tratamento viável para algumas situações de perdas dentárias. O presente trabalho tem por objetivo relatar um autotransplante dentário realizado em um paciente de 17 anos de idade com acompanhamento de 2 anos.

Palavras-chave: Terceiro molar. Erupção dentária. Transplante autólogo.

\begin{abstract}
The dental autotransplantation consists of a technique characterized by the replacement of a lost or missing element by a transplanted tooth, usually a third molar, for a pre-existing or surgically created alveolus. It is a relatively simple surgical technique, associated with success rates of $90 \%$. However, it may be influenced by patient's age, by root development phase, by tooth eruption and by other factors. Despite the possible complications of this technique, the economic advantages and the surgical time optimization, make this procedure a viable treatment option for some situations of tooth loss. This study aims to report the dental autotransplantation performed in a 17-year-old patient with a two-years follow-up.
\end{abstract}

Keywords: Third molar. Tooth eruption. Autologous transplantation.

\footnotetext{
${ }^{1}$ Cirurgiã Dentista

${ }^{2}$ Professor Mestre, Faculdade de Odontologia, Escola Superior da Amazônia

${ }^{3}$ Especialista em Cirurgia Bucomaxilofacial

${ }^{4}$ Mestrando em Odontologia, Centro Universitário do Estado do Pará

${ }^{5}$ Professor Doutor, Faculdade de Odontologia, Universidade Federal do Pará
} 


\section{INTRODUÇão}

A reabilitação de espaços edêntulos representa um grande desafio à odontologia, especialmente em perdas dentárias precoces, pelos aspectos estéticos e funcionais associados. Tradicionalmente, esta reabilitação vem sendo realizada por meio de próteses removíveis ou fixas e implantes osseointegrados ${ }^{1}$. Entretanto, essas modalidades terapêuticas resultam usualmente em desconforto durante o assentamento da prótese e no ato mastigatório, desgastes de dentes saudáveis ou estão contraindicadas em crianças e adolescentes até 17 anos em fase de crescimento ósseo ${ }^{1,2}$.

O autotransplante dentário é considerado uma excelente alternativa para reabilitação de perdas dentárias em adolescentes. Esta técnica consiste no reposicionamento de um dente autógeno no local da ausência dentária, por meio da exodontia do elemento indicado ou preparação de um alvéolo cirúrgico ${ }^{3}$.

O dente que vai ser transplantado deve ter dois terços de formação radicular, para um bom prognóstico ${ }^{4,5,6}$. Os elementos dentários que são perdidos mais precocemente são os primeiros e segundos molares, pois estes levam mais tempo em fase de infraoclusão, sendo mais suscetíveis à cárie ${ }^{7}$.

Estudos apontam altas taxas de sucesso para o autotransplante dentário, variando entre 82 a $94 \%{ }^{8,9}$. Entretanto, esta técnica também pode estar associada a complicações, incluindo a reabsorção radicular, anquilose do elemento dentário, desconforto na sondagem periodontal, além de bolsas com mais de 3 mm de profundidade ${ }^{2}$.

\section{Relato de Caso}

Paciente P.A.O., 17 anos, gênero masculino, compareceu ao Serviço de Cirurgia e Traumatologia Bucomaxilofacial de uma Instituição de Ensino Superior Pública, com indicação para exodontia do elemento 26. Ao exame clínico, constatou-se que o dente em questão apresentava uma lesão cariosa extensa, comprometendo toda a porção coronária do dente. O paciente não relatou histórico de doenças sistêmicas ou alergias medicamentosas.

Ao exame radiográfico periapical, observou-se uma lesão radiotransparente ampla ao redor dos remanescentes radiculares do dente 26 , sugerindo possivelmente um processo infeccioso local. Optou-se pela exodontia, associada à curetagem da lesão e antibioticoterapia com amoxicilina 500mg a cada 8 horas, por 7 dias (Figura 1).

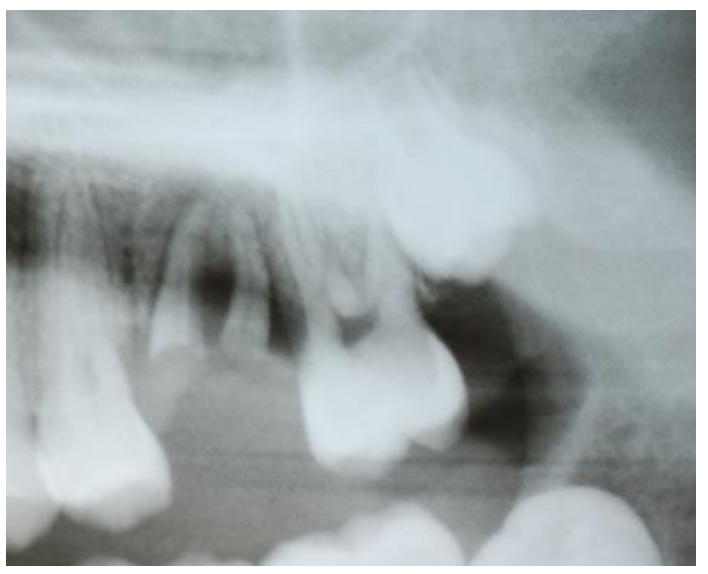

Figura 1 - Lesão de cárie extensa no elemento 26.

O pós-operatório de 7 dias da exodontia manteve-se sem intercorrências e 14 dias após este procedimento, foi realizado o autotransplante dentário do elemento 28 para o espaço do dente 26 (Figura 2). O procedimento foi realizado sob anestesia local dos nervos alveolar superior posterior e médio e ramos terminais dos nervos palatino maiores ipsilateralmente, utilizando mepivacaína a 2\% com adrenalina 1:100.000.

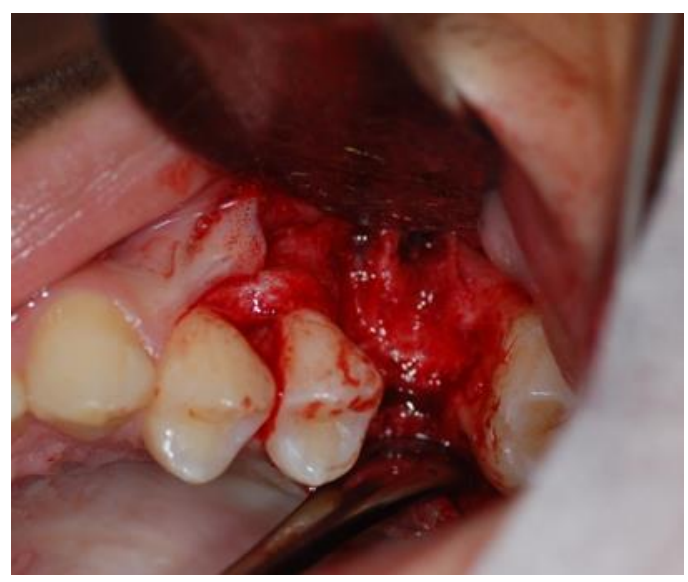

Figura 2 - Alvéolo do elemento 26 preparado para o transplante do dente 28. 
Em seguida, realizou-se um retalho triangular para exodontia do dente 28 associado a um descolamento mucoperiosteal para exposição ampla deste terceiro molar e menor traumatismo possível durante a remoção do mesmo. Além disso, foi feita a curetagem do tecido de granulação formado no alvéolo do dente 26 , bem como a remoção parcial do septo interdental com alveolótomo para a eliminação de interferências e melhor adaptação do elemento 28 .

O terceiro molar superior foi estabilizado com suturas utilizando fio de seda 4.0 em pontos no sentido vestíbulo-palatino. Além disso, certificou-se de que o elemento transplantado estava em desoclusão total em todos os movimentos mandibulares, não havendo, portanto, a necessidade de ajuste oclusal (Figuras $3 \mathrm{e}$ 4).

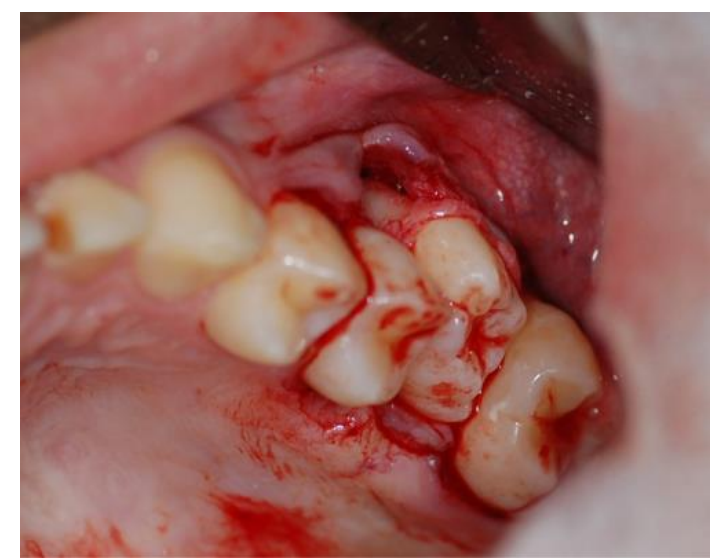

Figura 3 - Elemento 28 transplantado para o alvéolo resultante da exodontia.

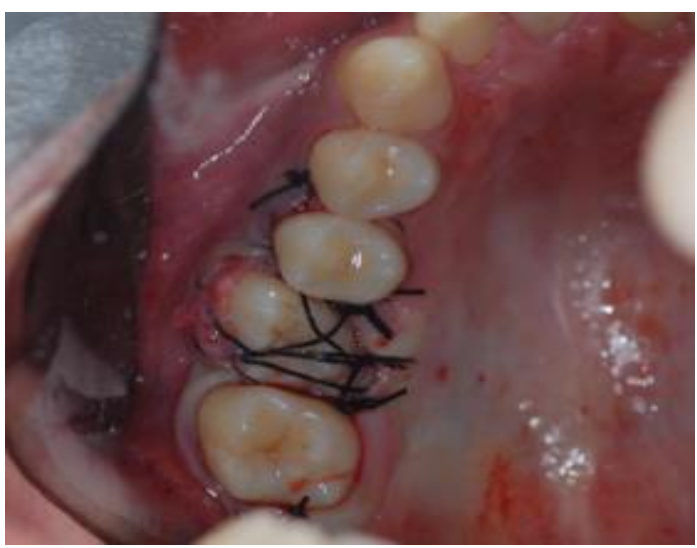

Figura 4 - Elemento 28 estabilizado por meio de sutura com pontos interrompidos.
O pós-operatório seguiu com amoxicilina $500 \mathrm{mg}$ a cada 8 horas por 7 dias, associado ao ibuprofeno 600 mg a cada 8 horas por 4 dias e dipirona sódica $500 \mathrm{mg}$ (40 gotas) a cada 6 h, além de bochecho não vigoroso, 3 vezes ao dia com digluconato de clorexidina a $0,12 \%$ por 10 dias.

Após 1 mês da realização do autotransplante, o elemento 28 já apresentava resposta positiva aos testes de vitalidade ao frio. Atualmente o paciente encontrase no pós-operatório de 2 anos, mantendo-se a vitalidade pulpar, com o dente em função oclusal e sem alterações periodontais (Figuras 5 e 6 ).

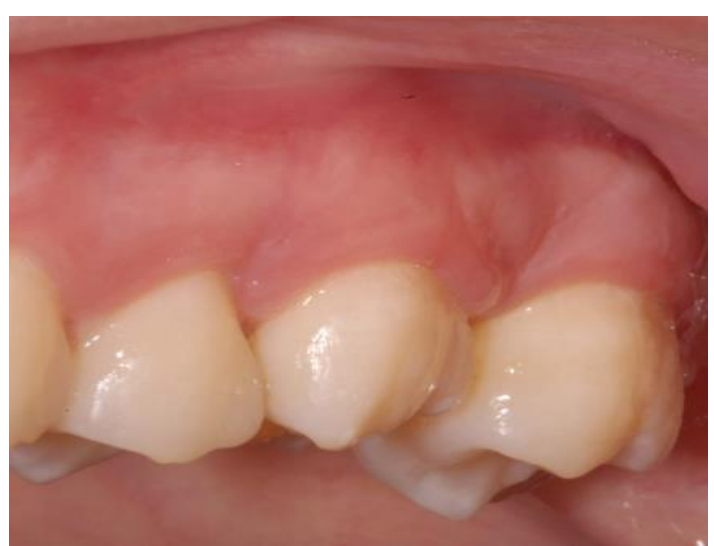

Figura 5 - Aspecto clínico em pós-operatório de 2 anos. Pode-se observar o elemento 28 assumindo nivelamento oclusal.

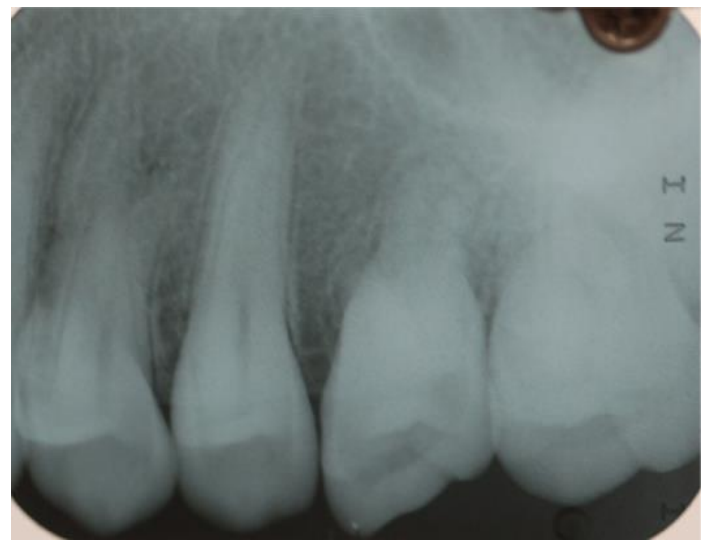

Figura 6 - Radiografia periapical pósoperatória de 2 anos. Pode-se observar a adaptação do elemento 28 ao periodonto, com rizogênese parcial. 


\section{Discussão}

A reabilitação de espaços protéticos em pacientes em crescimento ósseo é tecnicamente mais limitada, especialmente pela contraindicação de implantes osseointegrados nesta faixa etária. Diante disso, alternativas de tratamento têm sido discutidas para a restauração estética e funcional nesses pacientes, incluindo técnicas de autotransplante dentário ${ }^{10}$.

Segundo a literatura, pode-se dizer que os primeiros e segundos molares permanentes são os dentes que mais sofrem algum tipo de agressão externa e, consecutivamente, perda precoce. Isso ocorre pelo fato desses dentes apresentarem maior suscetibilidade à doença cárie, periodontite severa, trauma e insucesso endodôntico. Devido a esses fatores, o número de casos de cirurgias de autotransplante dentário é maior nestes dentes ${ }^{7}$.

O autotransplante dentário consiste na retirada de um dente, preparo do alvéolo e transplante imediato ou tardio que, no caso descrito, foi realizado após duas semanas de reparo alveolar. A literatura descreve altas taxas de sucesso para os autotransplantes dentários, variando entre $82 \%$ a $94 \%$. No entanto, alguns fatores, como os cuidados pré e pós-operatórios, devem ser respeitados e seguidos criteriosamente, bem como a indicação para a técnica, considerando alguns critérios como idade, estágio de formação radicular, técnica cirúrgica e técnicas de estabilização, pois os mesmos estão diretamente associados ao sucesso do tratamento $^{9,11}$.

A fase de rizogênese é um aspecto crucial. Existe um debate na literatura a respeito da fase de desenvolvimento radicular ideal para o autotransplante. Todavia, a maioria dos autores afirma que $1 / 2$ a $3 / 4$ do comprimento radicular total é uma boa fase para obter sucesso. Neste momento, o folículo embrionário está em plena atividade e o ápice radicular ainda não está fechado, preservando a vitalidade pulpar na maioria dos casos e dispensando um tratamento endodôntico futuro, além do fato de ser mais bem adaptado no leito receptor pelo seu menor tamanho, evitando possíveis fenestrações no alvéolo ${ }^{11,12,13}$.
Além disso, no autotransplante de um dente com rizogênese incompleta, há maior probabilidade de restabelecimento da vitalidade pulpar, evitando a necessidade de tratamento endodôntico, uma vez que os dentes imaturos contêm um rico suprimento vascular e de células tronco, sendo o desenvolvimento radicular dependente da preservação da bainha epitelial de Hertwig, ajudando também na cicatrização do periodonto ${ }^{14}$.

Por outro lado, o autotransplante dentário também pode ser realizado em dentes com desenvolvimento radicular completo, porém, com um prognóstico menos previsível. Nessa fase de rizogênese completa, após a cirurgia de autotransplante, Sugai et al. ${ }^{11}$ afirmam a necessidade de tratamento endodôntico logo após 3 a 4 semanas, pois a probabilidade de revascularização da polpa é mínima e, se não efetuado, pode ocorrer necrose pulpar e posterior infecção no periápice e no periodonto.

No que se refere à idade do paciente, os melhores resultados são obtidos em pessoas com menos de 20 anos, pois nesta fase, os terceiros molares ainda estão em fase de formação radicular. Além disso, é importante ressaltar também que o dente a ser reimplantado possua anatomia semelhante ao do leito receptor, para que não ocorram fenestrações no alvéolo $^{11,13}$.

No que se refere à técnica cirúrgica, é extremamente importante que as estruturas envolvidas sejam minimamente traumatizadas durante o ato cirúrgico ${ }^{11}$. Nesse aspecto, a preservação da vitalidade do ligamento periodontal aderido ao dente transplantado é fundamental, pois essa estrutura é suscetível a alterações do meio como o $\mathrm{pH}$, o potencial osmótico e o tempo de permanência extra-alveolar, o qual deve ser o menor possível, pois o ligamento periodontal após 18 minutos começa a tornar-se inviável pela necrose de suas fibras, quando expostas por tempo superior ao citado $^{3,7}$.

No protocolo de autotransplante dentário, há necessidade de estabilização do dente transplantado, a qual desempenha grande influência no prognóstico do procedimento. Essa etapa pode ser realizada pelas técnicas de contenção rígida ou semirrígida, onde a primeira consiste em estabilizar o dente pós-cirurgia 
com fios ortodônticos e compósitos e a semirrígida é realizada pela estabilização com fios de sutura ${ }^{10}$.

A literatura demonstra taxas de sucesso maiores para a contenção semirrígida, comparada com a fixação rígida, o que comprova o prognóstico menos favorável dessa última ${ }^{16,17}$. Essas diferenças residem no comprometimento do ligamento periodontal e do tecido pulpar decorrentes da estabilização rígida, pois a falta de mobilidade dentária resulta em anquilose e necroses pulpares ${ }^{7}$. Todavia, esta fixação rígida ainda pode ser necessária, especialmente em situações de falta de adaptação do dente autotransplantado no alvéolo receptor ${ }^{15,16}$.

Quanto ao momento do autotransplante dentário, as técnicas podem ser divididas em imediatas, quando o autotransplante é realizado no mesmo momento da exodontia; e mediatas, quando o autotransplante é realizado alguns dias após a exodontia do elemento relacionado ao leito receptor ${ }^{15,16}$, conforme realizado no caso clínico descrito. A técnica mediata também pode ser utilizada nas situações de perdas dentais precoces ou congênitas, onde, obrigatoriamente, há necessidade de criar um alvéolo cirurgicamente para receber o dente autotransplantado ${ }^{18}$.

Ao analisar comparativamente as duas técnicas, a literatura sugere melhores indicadores para $\mathrm{o}$ autotransplante imediato. Nesse procedimento, as principais vantagens incluem a facilidade na preparação do alvéolo receptor, a mínima manipulação do tecido ósseo, visto que necessita apenas da remoção do septo intra-alveolar, menor trauma cirúrgico, adaptação excelente do dente transplantado ${ }^{18}$, bem como preservação de células osteoprogenitoras nas paredes do alvéolo, o que pode favorecer a reparação alveolar'.

Por outro lado, na técnica mediata, diversas desvantagens são descritas, incluindo o maior trauma tecidual, visto que é necessário criar um alvéolo cirurgicamente no tecido ósseo receptor, maior risco de lesão térmica tecidual, retardamento do processo de revascularização local e prolongamento do período de reparação, resultando em um pior prognóstico para essa técnica ${ }^{9}$. Além disso, quando o autotransplante é realizado muito tempo após a perda dentária, há possibilidade de perda óssea horizontal no sítio receptor, comprometendo o suporte para o dente transplantado $^{18}$, o que não foi observado no caso clínico descrito, visto que o autotransplante foi realizado após 14 dias da exodontia do elemento 26 . A presença de infecção periapical foi o fator determinante para a escolha da técnica mediata, pois o processo infeccioso poderia comprometer o processo cicatricial ${ }^{2}$.

Além de todos os fatores já previamente descritos, o período pós-operatório também exerce influência sobre os índices de sucesso desta técnica, especialmente no que se refere à utilização de antibióticos e higienização adequada da área manipulada para evitar infecções ${ }^{7,11,16}$.

Algumas complicações podem ocorrer com o dente autotransplantado, onde irão depender de fatores locais, sistêmicos e pós-operatórios. Entre essas podemos citar reabsorção radicular, necrose do dente transplantado, doença periodontal com profundidade de sondagem maior que $4 \mathrm{~mm}$, culminando assim, para o insucesso da técnica ${ }^{7,10,11,16}$.

Neste contexto, alternativamente ao autotransplante, o fechamento de espaços protéticos pode ser realizado por meio de próteses convencionais ou sobre implante, como também pela movimentação ortodôntica ${ }^{15}$. No entanto, o paciente em questão refutou estas opções reabilitadoras. Além disso, no que se refere ao tratamento ortodôntico, como o terceiro molar ainda não estava irrompido, essa opção de tratamento tornava-se inviável, ao considerar-se, também, a otimização do tempo de tratamento.

\section{Conclusão}

A partir do referido caso clínico, sugere-se que o autotransplante dentário pode ser uma alternativa viável para o tratamento reabilitador, desde que sejam considerados de forma criteriosa todos os fatores importantes que concorrem para o sucesso da técnica, podendo-se evitar, desta forma, os aspectos negativos associados às outras opções terapêuticas reabilitadoras pertinentes. 


\section{REFERÊNCIAS}

1. Silva MHC, Lacerda MFLS, Chaves MGAM, Campos CN. Autotransplantation of a mandibular third molar: a case report with 5 years of follow-up. Braz Dent J. 2013; 24(3):289-94.

2. Nagori SA, Bhutia O, Roychoudhury A, Pandey RM. Immediate autotransplantation of third molars: an experience of 57 cases. Oral Surg Oral Med Oral Pathol Oral Radiol. 2014 oct;118(4): o400-7.

3. Bae JH, Choi YH, Cho BH, Kim YK, Kim SG. Autotransplantation of teeth with complete root formation: a case series. J Endod. 2010 aug;36(8):14226.

4. Atala-Acevedo C, Abarca J, Martínez-Zapata MJ, Díaz J, Olate S, Zaror C. Success rate of autotransplantation of teeth with an open apex: systematic review and metaanalysis. J Oral Maxillofac Surg. 2017 jan;75(1):35-50.

5. Teixeira CS, Pasternak B Jr, Vansan LP, Sousa-Neto MD. Autogenous transplantation of teeth with complete root formation: two case reports. Int Endod J. $2006 \mathrm{dec}$; 39(12):977-85.

6. Cohen AS, Shen TC, Pogrel MA. Transplanting teeth successfully: autografts and allografts that work. $J$ Am Dent Assoc. 1995 apr; 126(4):481-5.

7. Kumar R, Khambete N, Priya E. Successful immediate autotransplantation of tooth with incomplete root formation: case report. Oral Surg Oral Med Oral Pathol Oral Radiol. 2013 may;115(5):16-21.

8. Mejàre $\mathrm{B}$, Wannfors $\mathrm{K}$, Jansson $\mathrm{L}$. A prospective study on transplantation of third molar with complete root formation. Oral Surg Oral Med Oral Pathol Oral Radiol Endod. 2004 feb;97(2):231-8.

9. Tsukiboshi M. Autotransplantation of teeth: requirements for predictable success. Dent Traumatol. 2002 aug;18(4): 157-80.

10. Carvalho DRD, Macedo SB, Silva VR. Transplante dental autógeno de molares - revista da literatura. Rev. Odontol (ATO). 2013;13(5):364-85.

11. Sugai T, Yoshizawa M, Kobayashi T, Ono K, Takagi R, Kitamura N, et al. Clinical study on prognostic factors for autotransplantation of teeth with complete root formation. Int J Oral Maxillofac Surg. 2010 dec;39(12): 1193-203.

12. Alejandre OJJ. Transplantes dentários. Pract Odontol. 1991 out;12(10):17-9.

13. Consolaro A, Pinheiro TN, Intra JBG, Roldi A. Transplantes dentários autógenos: uma solução para casos ortodônticos e uma casuística Brasileira. Rev Dental Press Ortodon Ortop Facial. 2008 marapr;13(2): 23-8.

14. Jang JH, Lee SJ, Kim E. Autotransplantation of immature third molars using a computer-aided rapid prototyping model: a report of 4 cases. J Endod. 2013 nov;39(11): 1461-6.

15. Mendes RA, Rocha G. Mandibular third molar autotransplantation: literature review with clinical cases. J Can Dent Assoc. 2004 dec; 70(11):761-6.

16. Bauss O, Schilke R, Fenske C, Engelke W, Kiliaridis S. Autotransplantation of immature third molars: influence of different splinting methods and fixation periods. Dent Traumatol. 2002 dec;18(6):322-8.

17. Bauss O, Schwestka-Polly R, Schilke R, Kiliaridis S. Effect of different splinting methods and fixation periods on root development of autotransplanted immature third molars. J Oral Maxillofac Surg. 2005 mar;63(3):304-10.

18. Yu HJ, Jia P, Lv Z, Qiu LX. Autotransplantation of third molars with completely formed roots into surgically created sockets and fresh extraction sockets: a 10-year comparative study. Int J Oral Maxillofac Surg. 2017 apr; 46(4):531-8. 